\title{
The Relationship between Indo-Pacific Convection Oscillation and Summer Surface Air Temperature in Southern Asia
}

\author{
Jiayu Zheng ${ }^{1}$, Yanjie $\mathrm{Li}^{2}$, Jianping $\mathrm{Li}^{3}$, Jiaqing Xue ${ }^{3,4}$, \\ Yipeng Guo ${ }^{5}$, Ting Liu ${ }^{1}$, and Qiuyun Wang ${ }^{3}$ \\ ${ }^{1}$ State Key Lab of Satellite Ocean Environment Dynamics, Second Institute of Oceanography, Hangzhou, China \\ ${ }^{2}$ State Key Laboratory of Numerical Modeling for Atmospheric Sciences and Geophysical Fluid Dynamics, \\ Institute of Atmospheric Physics, Chinese Academy of Sciences, Beijing, China \\ ${ }^{3}$ College of Global Change and Earth System Sciences, Beijing Normal University, Beijing, China \\ ${ }^{4}$ University of Chinese Academy of Sciences, Beijing, China \\ ${ }^{5}$ Key Laboratory of Mesoscale Severe Weather/Ministry of Education, and School of Atmospheric Sciences, \\ Nanjing University, Nanjing, China
}

\begin{abstract}
The relationship between Indo-Pacific convection oscillation (IPCO) and summer (June-August) surface air temperature in southern Asia (including India and Indochina) is investigated for the period of 1979-2013 using observational datasets and a theoretical linear baroclinic model. In the summers with the positive IPCO phase, when the convection over the western North Pacific (north Indian Ocean) is enhanced (suppressed), the Southeast Asian summer monsoon is enhanced and the southern Asia is cooler than usual, and vice versa. The "positive-negative-positive" air temperature advection anomalies by anomalous wind play an important role in the negative relationship between the IPCO and surface air temperature in southern Asia. It is also found that this negative correlation is greatly enhanced in El Niño-Southern Oscillation decay years.
\end{abstract}

(Citation: Zheng, J., Y. Li, J. Li, J. Xue, Y. Guo, T. Liu, and Q. Wang, 2017: The relationship between Indo-Pacific convection oscillation and summer surface air temperature in southern Asia. SOLA, 13, 199-204, doi:10.2151/sola.2017-036.)

\section{Introduction}

Surface air temperature (SAT) is an important variable in climate studies. The SAT variation has received increasing attention in recent years due to the increased occurrences of heat waves, which often cause health problems and even many deaths (Trenberth et al. 2007; Wu et al. 2012). For example, the European summer heat wave of 2003 killed around 35,000 people across Europe (Fischer et al. 2007); the Russian summer heat wave of 2010 led to massive death toll, forest fires and crop failure over western Russia (Barriopedro et al. 2011; Sun et al. 2016); and the Ahmedabad heat wave of 2010 resulted in a great percentage increase in mortality in Ahmedabad, India (Azhar et al. 2014). Therefore, investigation of SAT variation around the world is of crucial importance.

For the SAT in India and Indochina, a number of studies focused on the long-term trend and turning point of the SAT (e.g., Hingane et al. 1985; Easterling et al. 1997; Kothawale and Rupa Kumar 2005; Dash and Mamgain 2011; Chooprateep and McNeil 2016). However, only a few studies investigated the interannual variability of the SAT in these regions. They showed that the interannual variability of the SAT in India and Indochina is affected by El Niño-Southern Oscillation (ENSO) (Quadir et al. 2004; Revadekar et al. 2009; Kothawale et al. 2010). Several studies also indicated that the interannual variability of the SAT in India

Corresponding author: Yanjie Li, Institute of Atmospheric Physics, Chinese Academy of Sciences, 40 Huayanli Road, Beijing 100029, China. E-mail: lyj@mail.iap.ac.cn. C 2017, the Meteorological Society of Japan. is not only remotely influenced by the ENSO, but also is locally influenced by sea surface temperature (SST) in the Indian Ocean (Chowdary et al. 2014; Panda et al. 2014). Thus, to get a better understanding of the SAT variation in India and Indochina, further investigations are needed.

Recently, the Indo-Pacific convection oscillation (IPCO), which is an out-of-phase convection fluctuation during summer over the Indo-western Pacific region, was proposed by $\mathrm{Li}$ et al. (2013). The IPCO has two poles, with one located over the north Indian Ocean (NIO), and the other over the tropical western North Pacific (WNP). It is found that the IPCO has a significant relationship with the East Asian summer monsoon. Zhang et al. (2015) indicated that the IPCO has a strong season-independent intraseasonal variation. Actually, southern Asia (including India and Indochina) is located right between the two poles of the IPCO; thus, the climate conditions in southern Asia may be connected with the IPCO. However, while previous studies focused on the effects of the IPCO on the East Asian summer monsoon or the intraseasonal variation of the IPCO, few researchers investigated the relationship between the IPCO and the climate conditions in southern Asia. In this paper, we reveal the relationship between the IPCO and the SAT in southern Asia.

\section{Data and methods}

The outgoing longwave radiation (OLR) data used in this paper are the interpolated OLR data on a $2.5^{\circ} \times 2.5^{\circ}$ grid from the U.S. National Oceanic and Atmospheric Administration (NOAA) (Liebmann and Smith 1996). For the SAT, we use the University of Delaware air temperature dataset on a $0.5^{\circ} \times 0.5^{\circ}$ grid (Willmott and Matsuura 2001); the Jones (CRU) Air Temperature Anomalies Version 3 (CRUTEM3) dataset (Brohan et al. 2006) and ERA Interim 2 meter temperature data (Dee et al. 2011) are used to verify the results. Other atmospheric variables are from the U.S. National Centers for the Environmental Prediction/National Center for Atmospheric Research (NCEP/NCAR) reanalysis I, including air temperature, wind speed on a $2.5^{\circ} \times 2.5^{\circ}$ grid, and downward shortwave radiation on the T62 Gaussian grid (Kalnay et al. 1996). These variables from ERA Interim dataset (Dee et al. 2011) are also used to verify the results. For the SST, we use the NOAA Extended Reconstructed SST V $3 b$ on a $2^{\circ} \times 2^{\circ}$ grid (Smith et al. 2008). Our study focus on the boreal summer (JJA) over the period from 1979 to 2013 .

The IPCO index (IPCOI) in this paper is defined by the difference of normalized OLR between NIO and WNP poles. Here, the NIO pole consists of the Arabian Sea $\left(55^{\circ} \mathrm{E}-75^{\circ} \mathrm{E}, 7.5^{\circ} \mathrm{N}-15^{\circ} \mathrm{N}\right)$ and south of the Bay of Bengal $\left(80^{\circ} \mathrm{E}-100^{\circ} \mathrm{E}, 5^{\circ} \mathrm{N}-12.5^{\circ} \mathrm{N}\right)$, while the WNP pole covers $125^{\circ} \mathrm{E}-160^{\circ} \mathrm{E}, 10^{\circ} \mathrm{N}-15^{\circ} \mathrm{N}$ ( $\mathrm{Li}$ et al. 2013 ). The extreme positive and negative IPCO years are identified as those exceeding \pm 1 standard deviation in the IPCOI. The extreme positive IPCO years are 1981, 1989, 1990, 2001, 2002, and 2004, 
whereas the extreme negative IPCO years are 1983, 1992, 1995, 1996, 1998, 2007, and 2010. The monsoon index is defined using the dynamical normalized seasonality (DNS) index, which is based on the intensity of the normalized seasonality of wind field (Li and Zeng 2002). The area-averaged DNS index is often used to describe the intensity of monsoons over different areas (Zheng et al. 2014). The South Asian summer monsoon (SASM) index (SASMI), Southwest Asian summer monsoon (SWASM) index (SWASMI), and Southeast Asian summer monsoon (SEASM) index (SEASMI) are defined as the JJA $850-\mathrm{hPa}$ DNS index averaged over South Asia $\left(35.0^{\circ} \mathrm{E}-97.5^{\circ} \mathrm{E}, 5.0^{\circ} \mathrm{N}-22.5^{\circ} \mathrm{N}\right)$, Southwest Asia $\left(35^{\circ} \mathrm{E}-70^{\circ} \mathrm{E}, 2.5^{\circ} \mathrm{N}-20.0^{\circ} \mathrm{N}\right)$, and Southeast Asia $\left(70^{\circ} \mathrm{E}-\right.$ $110^{\circ} \mathrm{E}, 2.5^{\circ} \mathrm{N}-20.0^{\circ} \mathrm{N}$ ), respectively. These monsoon indices can be obtained from the website of http://ljp.gcess.cn/dct/page/65576.

To illustrate the atmospheric circulation associated with the IPCO, a theoretical linear baroclinic model (LBM) (Watanabe and Kimoto 2000) is adopted in this study. The model has T42 resolution in the horizontal and 20 sigma levels in the vertical. It takes about 20 days for the LBM to approach a steady state (Zhao et al. 2015); thus, the experiments are run for 30 days, and the outputs from the last five days are used in the analysis.

a) $\operatorname{corr}(I P C O I$, OLR)
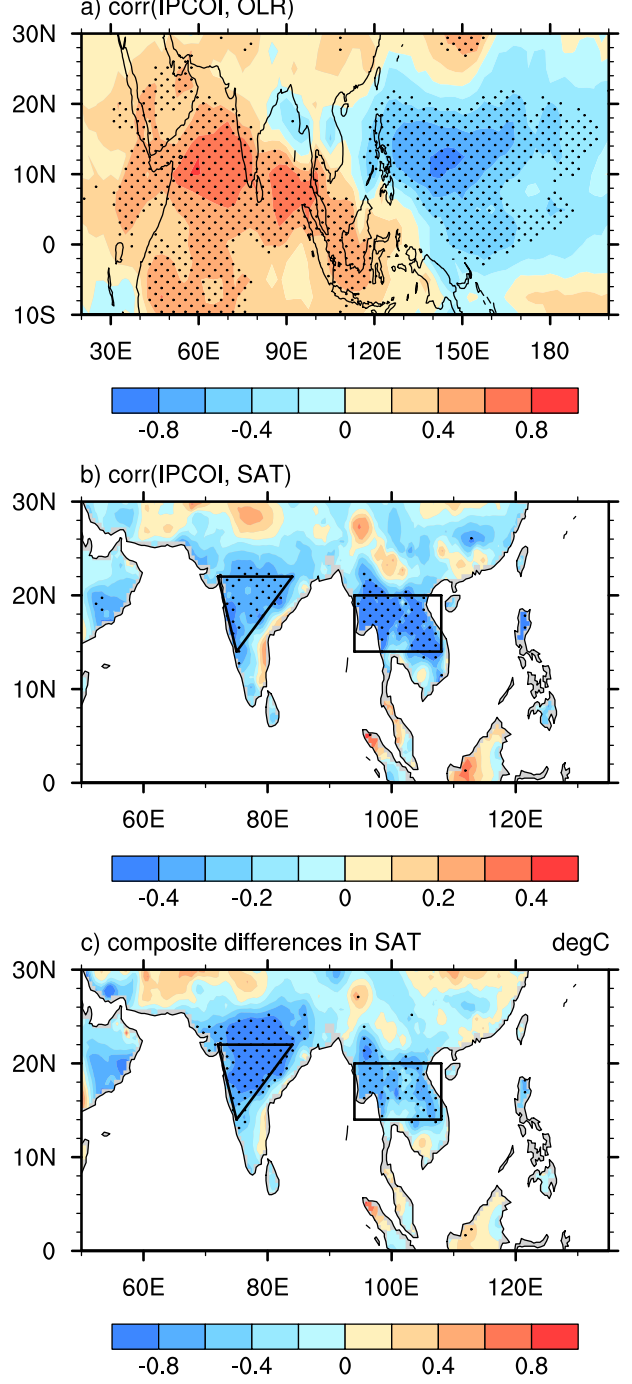

Fig. 1. (a) Correlation map between the IPCOI and JJA OLR during 1979-2013. (b) Same as (a), but for JJA SAT. (c) Composite differences in JJA SAT between the extreme positive and negative IPCO summers (unit: $\left.{ }^{\circ} \mathrm{C}\right)$. The stippled areas in (a-c) are significant at the $95 \%$ confidence level. The black triangle and rectangle in $(b, c)$ denote the India region and Indochina region, respectively.

\section{Results}

Figure 1a shows the correlation map between the IPCOI and OLR during JJA for the study period. A significant positive correlation exists in the NIO, whereas a significant negative correlation could be observed in the WNP. It shows that when the IPCO is in its positive phase, the convection over the NIO (WNP) is suppressed (enhanced), and vice versa. Figure $1 \mathrm{~b}$ presents the correlation map between the IPCOI and land SAT during JJA for the study period. It can be seen that two significant areas of negative correlation exist in India and Indochina. The correlation map using the CRUTEM3 SAT data or ERA 2 meter temperature data also has a similar structure (not shown). Consequently, we use the University of Delaware SAT data in the following analysis. Based on the correlation distribution in Figure 1b, the India region in this study is referred to the triangle region with three vertices located at $\left(72^{\circ} \mathrm{E}, 22^{\circ} \mathrm{N} ; 84^{\circ} \mathrm{E}, 22^{\circ} \mathrm{N} ; 75^{\circ} \mathrm{E}, 14^{\circ} \mathrm{N}\right)$, and the Indochina region in this study is referred to the rectangle region $\left(94^{\circ} \mathrm{E}-108^{\circ} \mathrm{E}\right.$, $\left.14^{\circ} \mathrm{N}-20^{\circ} \mathrm{N}\right)$, whereas the southern Asia region comprises the two regions we just defined. Figure 1c shows the composite differences in SAT between the extreme positive and negative IPCO summers. It is found that significantly negative SAT anomalies appear over India and Indochina, and the SAT anomalies in some regions of southern Asia (especially in India) between the positive and negative IPCO summers is below $-0.8^{\circ} \mathrm{C}$.

Figure 2 displays the time series of the IPCOI and summer SAT in India, Indochina and southern Asia. It shows that the variation of the IPCO is out of phase with the summer SAT in both India and Indochina (Fig. 2a). Table 1 shows that the correlation coefficient between the IPCOI and summer SAT in India is -0.39 , whereas the correlation coefficient between the IPCOI and summer SAT in Indochina is -0.55 . They are both significant above the $95 \%$ confidence level, indicating that the summer SAT
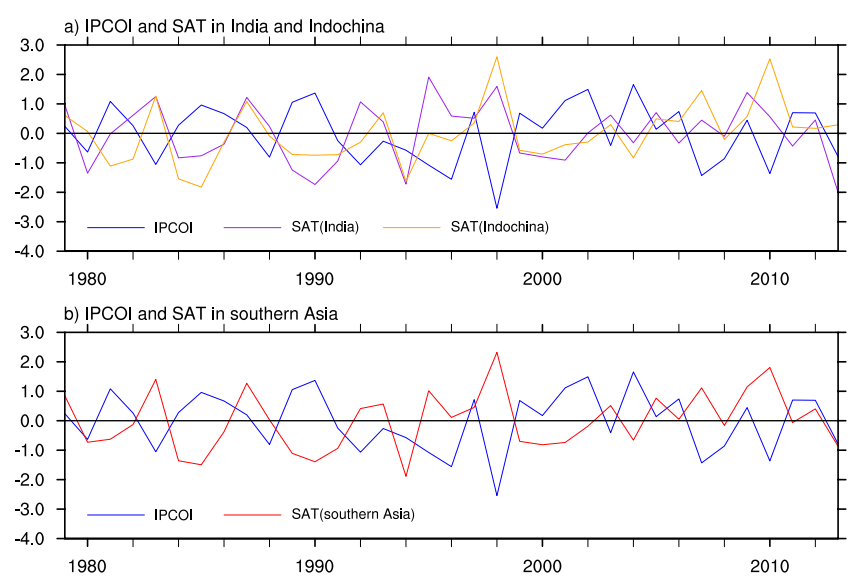

Fig. 2. (a) Standardized time series of the IPCOI (blue line), SAT in India (purple line), SAT in Indochina (orange line) during JJA for the period of 1979-2013. (b) As in (a), but for standardized time series of the IPCOI (blue line) and SAT in southern Asia (red line).

Table 1. Correlation coefficients among the IPCOI, SAT in India, SAT in Indochina and SAT in southern Asia during JJA for the period of 19792013.

\begin{tabular}{lccc}
\hline & $\begin{array}{c}\text { SAT } \\
\text { (India) }\end{array}$ & $\begin{array}{c}\text { SAT } \\
\text { (Indochina) }\end{array}$ & $\begin{array}{c}\text { SAT } \\
\text { (southern Asia) }\end{array}$ \\
\hline IPCOI & $-0.39^{*}$ & $-0.55^{*}$ & $-0.53^{*}$ \\
SAT (India) & $1.00^{*}$ & $0.58^{*}$ & $0.88^{*}$ \\
SAT (Indochina) & $0.58^{*}$ & $1.00^{*}$ & $0.90^{*}$ \\
SAT (southern Asia) & $0.88^{*}$ & $0.90^{*}$ & $1.00^{*}$ \\
\hline
\end{tabular}

The * indicates significant at the $95 \%$ confidence level using the Student's $t$-test. 
in India and Indochina are both associated with the IPCO. It also can be found that the summer SAT in India is in phase with the summer SAT in Indochina, with a correlation coefficient of 0.58 , which is significant at the $95 \%$ confidence level. Thus, the India region and the Indochina region could be treated as a whole. As expected, the correlation coefficient between the summer SAT in southern Asia and summer SAT in India (Indochina) is $0.88(0.90)$. They are both significant at the $95 \%$ confidence level, showing that the summer SAT in southern Asia could well express the summer SAT variations in India and Indochina. Furthermore, the correlation between the IPCOI and the summer SAT in the whole region (of southern Asia) is also significant with a correlation coefficient of -0.53 . When the IPCO is in its positive phase, there is a cooler summer in southern Asia, and vice versa (Fig. 2b). These results suggest that the IPCO has a large-scale relationship with the summer SAT in southern Asia, and the IPCO may connect with the summer SAT in both India and Indochina through similar physical mechanism.

Previous study showed that SAT anomalies are often caused by atmospheric circulation and radiation anomalies $(\mathrm{Hu}$ et al. 2011). To illustrate how the IPCO is related with the summer SAT in southern Asia, Figs. 3a, 3b, 3c, 3d, and 3e show the correlation or regression of these factors with the IPCOI for the study period. For vertical motion, only the vertical velocity in a fraction of a) $\operatorname{corr}($ IPCOI, OMEGA)

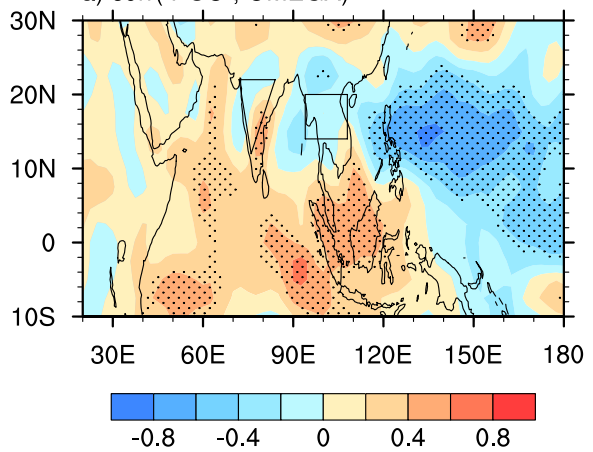

c) reg(IPCOI, wind)

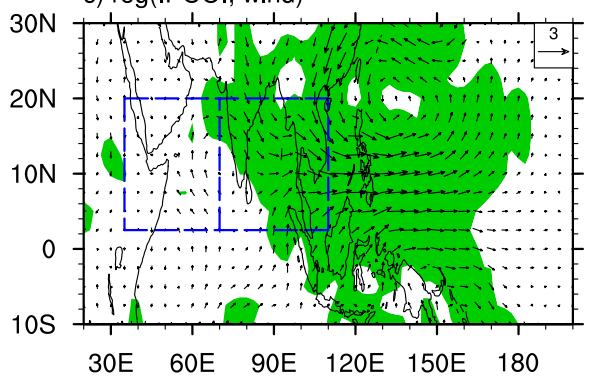

e) reg(IPCOI, -V.VT)

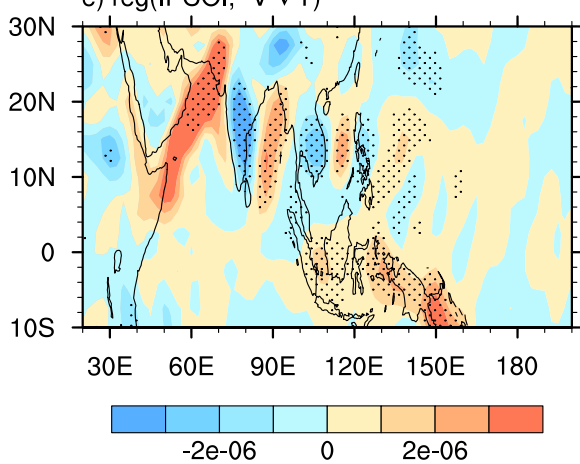

g) $\operatorname{reg}\left(\right.$ IPCOI, $\left.-\mathrm{V}^{\prime} \cdot \nabla \overline{\mathrm{T}}\right)$

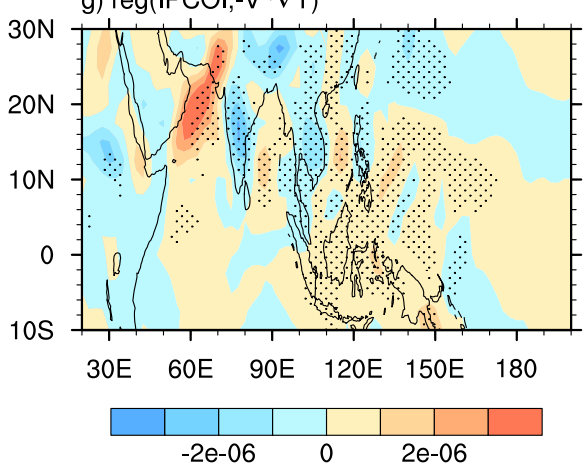

b) $\operatorname{corr}($ IPCOI, DSWRF)

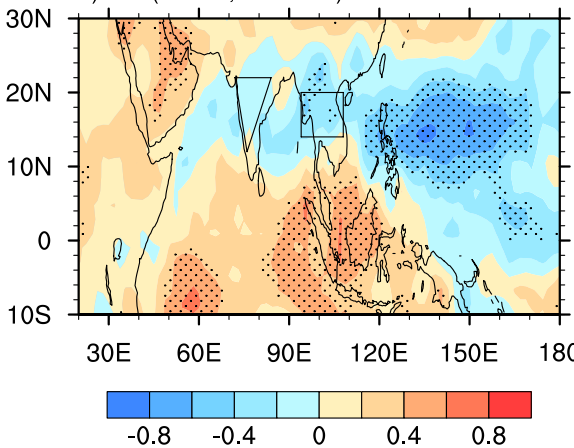

d) reg(IPCOI, meridionally-averaged wind)

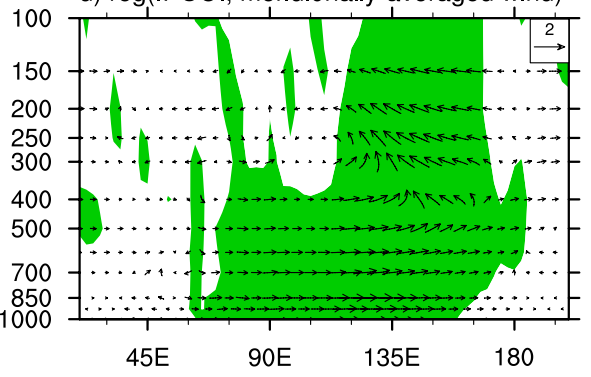

f) Mean JJA air temperature

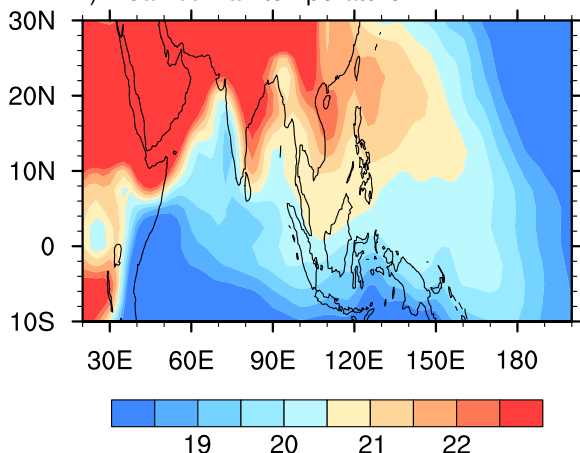

h) reg(SEASMI,-V' $\cdot \nabla \overline{\mathrm{T}})$

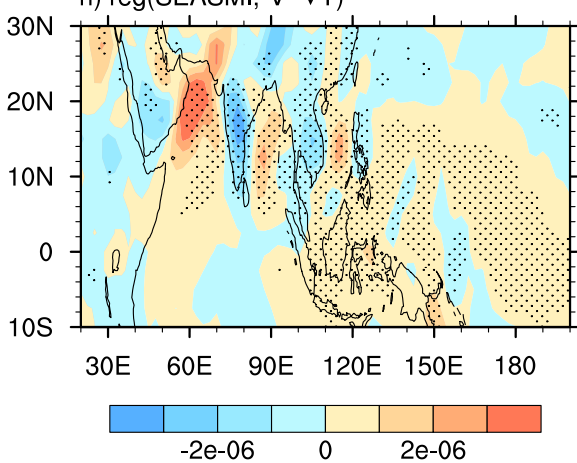

Fig. 3. (a) Correlations between the IPCOI and JJA 500-hPa vertical velocity during 19792013 (positive values denote subsidence). The stippled areas are significant at the $95 \%$ confidence level. (b) Same as (a), but for downward shortwave radiation (negative values denote less radiation). (c) Regression of JJA $850-\mathrm{hPa}$ wind anomalies (unit: $\mathrm{m} \mathrm{s}^{-1}$ ) against the IPCOI during 1979-2013. The zonal and meridional wind anomalies significant at $95 \%$ confidence level using F-test are shaded. The blue dashed rectangles in (c) denote the Southwest Asia and Southeast Asia, respectively. (d) Same as (c), but for meridionally-averaged wind anomalies over the latitude band of $12.5^{\circ} \mathrm{N}-17.5^{\circ} \mathrm{N}$ (unit of zonal and vertical wind: $\mathrm{m} \mathrm{s}^{-1}$ and $-10^{-2}$ $\mathrm{Pa} \mathrm{s}^{-1}$, respectively). The zonal and vertical wind anomalies significant at $95 \%$ confidence level using F-test are shaded. (e) Regression of JJA lower-level (vertical average of 925 to $850 \mathrm{hPa}$ ) air temperature horizontal advection anomalies (unit: ${ }^{\circ} \mathrm{C} \mathrm{s}^{-1}$ ) against the IPCOI during 1979-2013. The stippled areas are significant at the $95 \%$ confidence level. (f) Mean JJA lower-level (vertical average of 925 to 850 $\mathrm{hPa}$ ) air temperature averaged for the period 1979-2013 (unit: ${ }^{\circ}$ C). (g) Same as (e), but for the advection of mean temperature by anomalous wind. (h) Same as (g), but the SEASMI. (Data source in Fig. 3: NCEP/NCAR reanalysis I). 
India region (triangle region) is significantly positively correlated with the IPCOI (Fig. 3a), which could not explain the negative correlation between the IPCOI and SAT in India based on the theory that the downward movement results in warmer air temperature through adiabatic heating. For downward shortwave radiation, it is found that there is no significant correlation in India, whereas the significantly negative correlation with the IPCOI in some part of Indochina support the negative correlation between the SAT in Indochina and the IPCOI (Fig. 3b). The correlation map using ERA Interim downward shortwave radiation data is consistent with Fig. 3b (not shown), showing that shortwave radiation anomalies associated with the IPCO could explain the SAT anomalies only in some region of Indochina in this study.

For horizontal atmospheric circulation anomalies at $850 \mathrm{hPa}$, there are cyclonic anomalies located over the WNP and anticyclonic anomalies located over the NIO, with the westerly anomalies appearing over both India and Indochina (Fig. 3c). And the anomalous zonal overturning circulation shows an anticlockwise movement (Fig. 3d), which is consistent with the finding of $\mathrm{Li}$ et al. (2013). Figure 3e presents the regression of lower-level (vertical average of 925 to $850 \mathrm{hPa}$ ) air temperature horizontal advection against the IPCOI; it is interesting to see that a train of "positive-negative-positive" significant centers extend from the Arabian Sea to the Philippine Sea. Particularly, two significant areas of negative air temperature advection anomalies exist in the India region and the Indochina region. Figure $3 \mathrm{f}$ shows the mean JJA air temperature averaged for period 1979-2013. The air temperature over India and Indochina is higher than that over the sea around India and Indochina. To examine the role of wind anomalies in the air temperature horizontal advection anomalies, a linear decomposition was applied to the air temperature horizontal advection. According to Eq. (1), the air temperature horizontal advection could be decomposed into four items (Wang et al. 2010),

$$
\begin{aligned}
-V \cdot \nabla \mathrm{T} & =\left(\bar{V}+V^{\prime}\right) \cdot \nabla(\overline{\mathrm{T}}+\mathrm{T}) \\
& =-\bar{V} \cdot \nabla \overline{\mathrm{T}}-V^{\prime} \cdot \nabla \overline{\mathrm{T}}-\bar{V} \cdot \nabla \mathrm{T}^{\prime}-V^{\prime} \cdot \nabla \mathrm{T}^{\prime}
\end{aligned}
$$

The $V, \mathrm{~T}$ and $\nabla$ in Eq. (1) denote the horizontal wind velocity, temperature and horizontal gradient operator, whereas the overbar and the prime represent the mean and the anomalies with respect to the mean during the period from 1979 to 2013. The first to the fourth items denote the mean air temperature advection, the advection of mean temperature by anomalous wind, the advection of anomalous temperature by mean wind and the nonlinear advection, respectively. It can be seen that the regression pattern of the air temperature advection by anomalous wind against the IPCOI (Fig. 3g) is similar with the regression of the air temperature advection against the IPCOI (Fig. 3e). The regressions using ERA Interim data also show similar structures. It implies that the anomalous westerlies at lower levels associated with the positive IPCO events could bring more relatively cool air from the sea to the land
Table 2. Correlation coefficients between the IPCOI and variable X, where $\mathrm{X}$ is SASMI, SWASMI, SEASMI, and SAT in southern Asia with the SEASMI removed during JJA for the period of 1979-2013.

\begin{tabular}{ccccc}
\hline & SASMI & SWASMI & SEASMI & $\begin{array}{c}\text { SAT (southern Asia) } \\
\text { with SEASMI removed }\end{array}$ \\
\hline IPCOI & 0.20 & -0.12 & $0.74^{*}$ & 0.00
\end{tabular}

The * indicate significant at the $95 \%$ confidence level using the Student's $t$-test.

(from the Arab sea to India, from the Bay of Bengal to Indochina), and favor a cooler summer in southern Asia, and vice versa.

Based on the analysis above, we suppose the SASM plays an important role in the relationship between the IPCO and the SAT in southern Asia. The SASM contains two independent components, SWASM over the Southwest Asia (rectangle on the left in Fig. 3c) and SEASM over the Southeast Asia (rectangle on the right in Fig. 3c) with quite different circulation structures (Wang and Fan 1999; Li and Zeng 2002). As shown in Table 2, the IPCOI is significantly correlated with the SEASMI only, whereas the IPCOI has no significant correlation with the SASMI and SWASMI. These results are consistent with Fig. 3c, in which the anomalous westerlies associated with the IPCO almost cover the Southeast Asia. With the SEASM signal removed by linear regression with respect to the SEASMI, the significant correlation between the IPCOI and SAT in southern Asia becomes insignificant, with a correlation coefficient of 0.00 . In addition, the regression pattern of the air temperature advection by anomalous wind against the SEASMI also has a train of "positive-negative-positive" centers (Fig. 3h). These all support that the IPCO connect with the SAT in southern Asia through the SEASM.

To detect the relationship between the IPCO and wind anomalies or SAT anomalies over southern Asia, a numerical experiment is performed using heatings associated with the positive IPCO events in the LBM. The heating we imposed in the LBM has a gamma profile with the peak at $400 \mathrm{hPa}(0.45 \sigma)$. The maximum heating rate over the WNP is set to $2 \mathrm{~K}$ day $^{-1}$ at $\left(140^{\circ} \mathrm{E}\right.$, $15^{\circ} \mathrm{N}$ ), whereas the minimum heating rate over the NIO is set to $-1 \mathrm{~K}$ day $^{-1}$ at $\left(75^{\circ} \mathrm{E}, 10^{\circ} \mathrm{N}\right)$, for the precipitation anomalies associated with the IPCO over the WNP is approximately twice of that over the NIO. Figure 4 shows the responses of $850-\mathrm{hPa}$ wind fields and 950-hPa air temperature in the "IPCO+" experiment. It can be seen that positive IPCO events tend to induce anomalous anticyclone (cyclone) over the NIO (WNP), anomalous westerlies over southern Asia (Fig. 4a) and negative SAT anomalies in southern Asia (Fig. 4b). It seems that the SAT anomalies could be forced by the heating associated with the IPCO, even though water vapor and shortwave radiation are eliminated. On the other hand, the SAT anomalies in the "IPCO+" experiment is weaker than
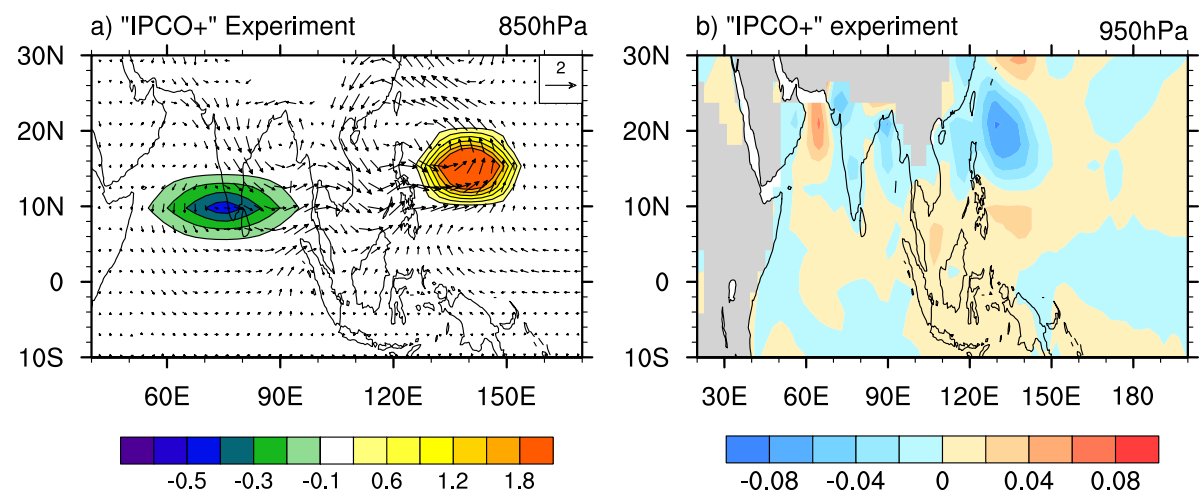

Fig. 4. (a) The response of $850-\mathrm{hPa}$ winds (vector, unit: $\mathrm{m} \mathrm{s}^{-1}$ ) in the "IPCO+" experiment. The heating imposed has a gamma profile with the peak at $400 \mathrm{hPa}$. The contours in (a) denote the heating at $400 \mathrm{hPa}$ (unit: $\mathrm{K}^{-1}{ }^{-1}$ ), and the contour interval of negative (positive) heating is $0.1(0.3) \mathrm{K}^{-1}{ }^{-1}$. (b) The response of near surface $(950-\mathrm{hPa})$ air temperature (unit: $\left.{ }^{\circ} \mathrm{C}\right)$ in the "IPCO+" experiment. 
that in observations (approximately half of Fig. 1c). This is possibly partly due to the weaker wind anomalies in the "IPCO+" experiment than that in observations, and possibly partly due to the lack of moisture process and radiation in the LBM. Over all, the wind anomalies and SAT anomalies pattern in the "IPCO+" experiment are consistent with observational datasets, suggesting that the heating anomalies associated with the IPCO are the key to the wind and SAT anomalies over southern Asia.

Figures $5 \mathrm{a}$ and $5 \mathrm{~b}$ show the correlation map between the IPCOI or SAT in southern Asia and simultaneous JJA SST during 1979-2013. It is found that a region of significant correlation both exist in the NIO. The NIO SST in this study is defined as the area-averaged SST in the region $\left(50^{\circ} \mathrm{E}-105^{\circ} \mathrm{E}, 10^{\circ} \mathrm{N}-20^{\circ} \mathrm{N}\right)$. Figures $5 \mathrm{c}$ and $5 \mathrm{~d}$ present the correlation map between the IPCOI or SAT in southern Asia and preceding DJF SST for the study period, displaying an ENSO-like pattern with significant correlation located in the Niño 3.4 region. The simultaneous NIO SST anomalies in JJA (Figs. 5a and 5b) are likely to be a response to ENSO in the preceding boreal winter (Klein et al. 1999). Figures $5 \mathrm{a}$ and $5 \mathrm{c}$ show that the IPCOI is significantly correlated with the decay phase of ENSO; the IPCO tend to be in a negative phase in the El Niño decay summer, whereas the IPCO tend to be in a positive phase in the La Niña decay summer. Figures $5 \mathrm{~b}$ and $5 \mathrm{~d}$ show that the SAT in southern Asia is also significantly correlated with the decay phase of ENSO, which is different from the result of Chowdary et al. (2014) that the SAT variation over India is primarily influenced by the developing phase of ENSO. To examine the role of SST in the relationship between the IPCO and the SAT in southern Asia, Fig. 5e (5f) shows the partial correlation map between the IPCOI and JJA SAT with the preceding DJF Niño 3.4 (the simultaneous JJA NIO SST) subtracted. It is observed that SAT in most parts of southern Asia has no significant correlation with the IPCOI after removing the preceding DJF Niño 3.4 or the simultaneous JJA NIO SST, indicating that the negative correlation between the IPCO and the SAT in southern Asia is greatly enhanced in ENSO decay years.

\section{Concluding remarks}

We demonstrate in this paper the relationship between the IPCO and boreal summer SAT in southern Asia (including India and Indochina) during 1979-2013. The IPCO is an important mode of variability in convection activity over the Indo-western Pacific region, which is characterized by suppressed (enhanced) convection over the NIO and enhanced (suppressed) convection over the WNP. It is found that the IPCO has a significant correlation with the SAT in southern Asia. In the summers with a positive IPCO phase, the SEASM is enhanced and the southern Asia is cooler than usual, and vice versa. Anomalous horizontal advection of mean temperature by anomalous wind plays an important role in the negaitve relationship between the IPCO and SAT in south-
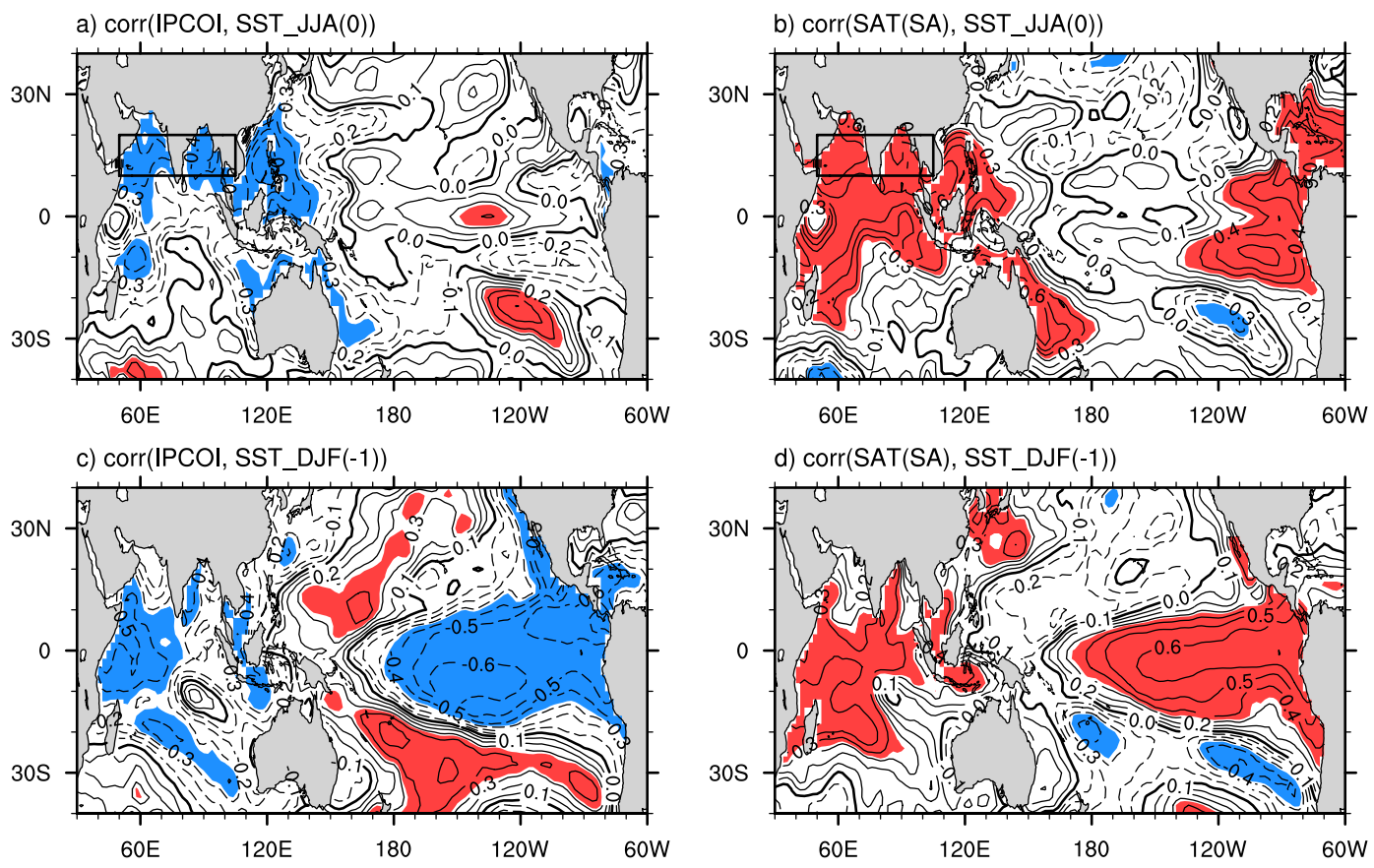

e) corr(IPCOI, SAT) with DJF(-1) NINO3.4 removed
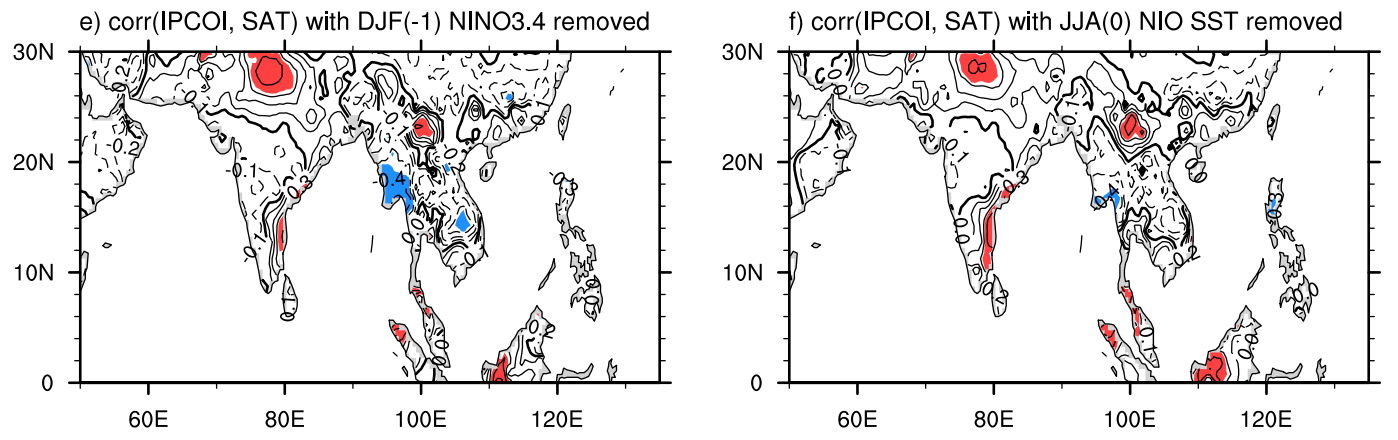

Fig. 5. Correlations (a-d) or partial correlations (e, f) between (a) the IPCOI and simultaneous JJA SST, (b) JJA SAT in southern Asia and simultaneous JJA SST, (c) the IPCOI and preceding DJF SST, (d) JJA SAT in southern Asia and preceding DJF SST, (e) the IPCOI and JJA SAT with the preceding DJF Niño 3.4 removed and (f) the IPCOI and JJA SAT with the simultaneous JJA NIO SST removed during 1979-2013. The contour interval is 0.1, and the areas significant at the $95 \%$ confidence level are shaded. Black rectangle in $(\mathrm{a}, \mathrm{b})$ denotes the NIO SST region used in the study. 
ern Asia. It is also found that this negative correlation is greatly enhanced in ENSO decay years.

Different from previous studies (Kothawale and Rupa Kumar 2002; Quadir et al. 2004; Chowdary et al. 2014), we highlight the relationship between the IPCO and the SAT in southern Asia. In this study, we found that the "positive-negative-positive" air temperature advection anomalies associated with the IPCO play an important role in the relationship between the IPCO and the SAT in southern Asia. Our results provide a new perspective to understand the SAT variation in southern Asia, and suggest that the local SAT prediction may be improved by accurate forecast of the IPCO.

\section{Acknowledgements}

This work was mainly supported by the National Natural Science Foundation of China (41690120 and 41690121), the scientific research fund of the Second Institute of Oceanography, SOA, China (14258-50), the National Natural Science Foundation of China (41621064 and 41505074), the National Basic Research Program (2013CB430302) and the National Program on Global Change and Air-Sea Interactions (GASI-IPOVAI-04 and GASIIPOVAI-03).

Edited by: Y. Kosaka

\section{References}

Azhar, G. S., D. Mavalankar, A. Nori-Sarma, and co-authors, 2014: Heat-related mortality in India: Excess all-cause mortality associated with the 2010 Ahmedabad heat wave. PLoS ONE, 9, e91831.

Barriopedro, D., E. M. Fischer, J. Luterbacher, and co-authors, 2011: The hot summer of 2010: Redrawing the temperature record map of Europe. Science, 332, 220-224.

Brohan, P., J. J. Kennedy, I. Harris, and co-authors, 2006: Uncertainty estimates in regional and global observed temperature changes: A new data set from 1850. J. Geophys. Res. Atmos., 111, D12106.

Chooprateep, S., and N. McNeil, 2016: Surface air temperature changes from 1909 to 2008 in Southeast Asia assessed by factor analysis. Theor. Appl. Climatol., 123, 361-368.

Chowdary, J. S., N. John, and C. Gnanaseelan, 2014: Interannual variability of surface air-temperature over India: Impact of ENSO and Indian Ocean sea surface temperature. Int. J. Climatol., 34, 416-429.

Dash, S. K., and A. Mamgain, 2011: Changes in the frequency of different categories of temperature extremes in India. $J$. Appl. Meteor. Climatol., 50, 1842-1858.

Dee, D. P., S. M. Uppala, A. J. Simmons, and co-authors, 2011: The ERA-Interim reanalysis: Configuration and performance of the data assimilation system. Quart. J. Roy. Meteor. Soc., 137, 553-597.

Easterling, D. R., B. Horton, P. D. Jones, and co-authors, 1997: Maximum and minimum temperature trends for the globe. Science, 277, 364-367.

Fischer, E. M., S. I. Seneviratne, D. Lüthi, and C. Schär, 2007: Contribution of land-atmosphere coupling to recent European summer heat waves. Geophys. Res. Lett., 34, L06707.

Hingane, L. S., K. Rupa Kumar, and B. V. Ramana Murty, 1985: Long-term trends of surface air temperature in India. Int. J. Climatol., 5, 521-528.

Hu, K., G. Huang, and R. Huang, 2011: The impact of tropical Indian Ocean variability on summer surface air temperature in China. J. Climate, 24, 5365-5377.

Kalnay, E., M. Kanamitsu, R. Kistler, and co-authors, 1996: The NCEP/NCAR 40-year reanalysis project. Bull. Amer. Meteor. Soc., 77, 437-471.

Klein, S. A., B. J. Soden, and N.-C. Lau, 1999: Remote sea surface temperature variations during ENSO: Evidence for a tropical atmospheric bridge. J. Climate, 12, 917-932.

Kothawale, D. R., A. A. Munot, and K. Krishna Kumar, 2010: Surface air temperature variability over India during 19012007, and its association with ENSO. Climate Res., 42, 89104.

Kothawale, D. R., and K. Rupa Kumar, 2002: Tropospheric temperature variation over India and links with the Indian summer monsoon: 1971-2000. Mausam, 53, 289-308.

Kothawale, D. R., and K. Rupa Kumar, 2005: On the recent changes in surface temperature trends over India. Geophys. Res. Lett., 32, L18714.

Li, J., and Q. Zeng, 2002: A unified monsoon index. Geophys. Res. Lett., 29, 1274.

Li, Y., J. Li, and J. Feng, 2013: Boreal summer convection oscillation over the Indo-Western Pacific and its relationship with the East Asian summer monsoon. Atmos. Sci. Lett., 14, 6671.

Liebmann, B., and C. A. Smith, 1996: Description of a complete (interpolated) outgoing longwave radiation dataset. Bull. Amer. Meteor. Soc., 77, 1275-1277.

Panda, D. K., A. Mishra, A. Kumar, and co-authors, 2014: Spatiotemporal patterns in the mean and extreme temperature indices of India, 1971-2005. Int. J. Climatol., 34, 3585-3603.

Quadir, D. A., M. L. Shrestha, T. M. A. Khan, and co-authors, 2004: Variations of surface air temperature over the land areas in and around the Bay of Bengal. Nat. Hazards, 31, $561-584$.

Revadekar, J. V., D. R. Kothawale, and K. Rupa Kumar, 2009: Role of El Niño/La Niña in temperature extremes over India. Int. J. Climatol., 29, 2121-2129.

Smith, T. M., R. W. Reynolds, T. C. Peterson, and J. Lawrimore, 2008: Improvements to NOAA's historical merged landocean surface temperature analysis (1880-2006). J. Climate, 21, 2283-2296.

Sun, C., J. Li, and R. Ding, 2016: Strengthening relationship between ENSO and western Russian summer surface temperature. Geophys. Res. Lett., 43, 843-851.

Trenberth, K. E., P. D. Jones, P. G. Ambenje, and co-authors, 2007: Observations: Surface and atmospheric climate change. Climate Change 2007: The Physical Science Basis. Contribution of Working Group 1 to the Fourth Assessment Report of the Intergovernmental Panel on Climate Change, S. Solomon, D. Qin, M. Manning, and co-authors, Eds., Cambridge University Press, Cambridge.

Wang, B., and Z. Fan, 1999: Choice of South Asian summer monsoon indices. Bull. Amer. Meteor. Soc., 80, 629-638.

Wang, C., H. Liu, and S.-K. Lee, 2010: The record-breaking cold temperatures during the winter of 2009/2010 in the Northern Hemisphere. Atmos. Sci. Lett., 11, 161-168.

Watanabe, M., and M. Kimoto, 2000: Atmosphere-ocean thermal coupling in the North Atlantic: A positive feedback. Quart. J. Roy. Meteor. Soc., 126, 3343-3369.

Willmott, C. J., and K. Matsuura, 2001: Terrestrial air temperature and precipitation: monthly and annual time series (19501999) (Available online at http://climate.geog.udel.edu/ climate/html_pages/README.ghcn_ts2.html, accessed on 11 April 2017).

Wu, Z., H. Lin, J. Li, and co-authors, 2012: Heat wave frequency variability over North America: Two distinct leading modes. J. Geophys. Res. Atmos., 117, D02102.

Zhang, J., J. Li, and Y. Li, 2015: Intraseasonal characteristics of the Indo-west Pacific convection oscillation. Chinese $J$. Atmos. Sci., 39, 221-234 (in Chinese).

Zhao, S., J. Li, and Y. Li, 2015: Dynamics of an interhemispheric teleconnection across the critical latitude through a southerly duct during boreal winter. J. Climate, 28, 7437-7456.

Zheng, J., J. Li, and J. Feng, 2014: A dipole pattern in the Indian and Pacific oceans and its relationship with the East Asian summer monsoon. Environ. Res. Lett., 9, 074006.

Manuscript received 23 August 2017, accepted 1 October 2017

SOLA: https://www.jstage.jst.go.jp/browse/sola/ 